\title{
Comparative Studies on Therapeutic Efficacy Intrauterine Turmeric Extract and Ceftiofur Sodium Alone and in Combination with Micronutrients Supplementation in Postpartum Metritic Crossbred Cows
}

Rajender Kumar, Sant Prasad Nema, Sobaran Sing Mahour, Ashok Kumar Patil, Madhu Shivhare, Vinita

10.18805/IJAR.B-4486

\begin{abstract}
Background: The postpartum period is crucial in dairy cows and is marked by major physiological and metabolic changes that affect milk production, immune response and fertility. Nutrition remains the most important lever for limiting the negative energy balance and its consequences on general health status in highly selected dairy cows. Therefore, the present study is design to investigate the Therapeutic efficacy intrauterine turmeric extract and ceftiofur sodium alone and in combination with micronutrients supplementation in postpartum metritic crossbred cows.

Methods: The present study was conducted on 24 crossbred cows with history of postpartum metritis randomly divided into four treatment groups: intrauterine turmeric extract (group I), intramuscular ceftiofur sodium (group II), intrauterine turmeric extract + micronutrient supplementation (group III) and intramuscular ceftiofur sodium + micronutrient supplementation (group IV).

Result: The mean time interval required for resumption of cyclicity was highest in gp II followed by gp I, gp III and gp IV. The group turmeric extract + micronutrients supplementation and ceftiofur sodium + micronutrients supplementation group registered a considerable higher conception rate (66.66) followed by $(50 \%)$ in turmeric extract and ceftiofur sodium group.
\end{abstract}

Key words: Ceftiofur sodium, Conception rate, Micronutrient supplementation, Postpartum metritis, Turmeric extract.

\section{INTRODUCTION}

Postpartum metritis is one of the most important disorders in cows causing high economic losses due to prolonged open days and inter-calving intervals, resulting in involuntary culling of animal. Postpartum metritis is clinically characterized by incomplete or delayed uterine involution, enlarged uterus on rectal palpation with exhibiting varying amount of purulent mucopurulent discharge through vulva, reduced appetite and milk yield (Bhaumik et al., 1992 and Cairoli et al., 1993). It is more common in early postpartum period as uterus is exposed to high risk of infection (Walia et al., 2010). To reduce these high economic losses effective ameliorative measures are needed.

Presently, treatment of such infertility is mainly achieved using intrauterine antibiotics, antiseptics and less commonly by hormones. The inconsistent results, high cost of treatment, compulsory milk disposal and inhibition of natural uterine defense, emergence of resistant bacterial strains, after antibiotic/antiseptic treatment made it unethical and uneconomical (Hussain and Daniel, 1992, Sarkar et al., 2016). Now a day, the major problem faced by the world is the multiple drug resistance pathogens (MDR) because of the indiscriminate use of commercial antimicrobial drugs. Plants used for traditional medicine contain a wide range of bioactive molecules, making them rich sources of different types of medicine particularly antimicrobial properties (Sarkar et al., 2016, Nair et al., 2005). Antimicrobials of plant
Department of Veterinary Gynaecology and Obstetrics, College of Veterinary Sciene and Animal Husbandry, Mhow-453 441, Madhya Pradesh, India.

Corresponding Author: Madhu Shivhare, Department of Veterinary Gynaecology and Obstetrics, College of Veterinary Sciene and Animal Husbandry, Mhow-453 441, Madhya Pradesh, India.

Email: drmadhushivhare@gmail.com

How to cite this article: Kumar, R., Nema, S.P., Mahour, S.S., Patil, A.K., Shivhare, M. and Vinita. (2021). Comparative Studies on Therapeutic Efficacy Intrauterine Turmeric Extract and Ceftiofur Sodium Alone and in Combination with Micronutrients Supplementation in Postpartum Metritic Crossbred Cows. Indian Journal of Animal Research. DOI: 10.18805/IJAR.B-4486.

Submitted: 13-04-2021 Accepted: 02-07-2021 Online: 03-08-2021

origin have enormous therapeutic potential (Cunha, 2001) They are effective in the treatment of infectious diseases while simultaneously minimizing many of the side effects that are often associated with synthetic antimicrobials or antibiotics. There are many published reports on the effectiveness of traditional plants against Gram positive and Gram negative microorganisms and as a result, plants are still recognized as the basis for modern medicine to treat infectious diseases (Evans, 2002).

Turmeric (Curcuma longa) exhibit immunomodulatory, antiinflammatory, antifungal, antibacterial, antiviral and 
antioxidant properties to resolve the problem without facing antibiotic resistance and milk disposal problem (Ghazanfari et al., 2002, Subapriya and Nagini, 2005). Similarly, Minerals and vitamins have direct or indirect relationship with productive and reproductive health of animals. Deficiencies and imbalance of minerals during peri-parturient period are either solely incriminated for or associated with anestrous (Patil and Deshpande, 1979; Agarwal et al., 1985; Singh and Vadnere, 1987), repeat breeding (Prajapati et al., 2005), metabolic disorders, retention of foetal membranes (Gupta et al., 2005), dystocia, abortion (Sharma et al., 2005), weak calf syndrome (Logan et al., 1990), milk fever, vulval discharge (Husband, 2006) and poor conception rate (Khasatiya et al., 2005 , Abdullah et al., 2017). Thus have negative impact on the subsequent fertility of the cow. Keeping all those useful effects of turmeric and micronutrients in mind, the current study is designed to investigate the therapeutic efficacy of intrauterine turmeric extract and ceftiofur sodium alone and in combination with micronutrients supplementation in postpartum metritic crossbred cows.

\section{MATERIALS AND METHODS}

The study was carried out on clinical cases brought to the Teaching Veterinary Clinical Complex of College of Veterinary Science and A.H., Mhow and in villages in and around Mhow.

\section{Experimental design}

The postpartum metritic dairy cows $(n=24)$ were randomly selected on the basis of calving history, gynaeco-clinical findings such as presence of abnormal uterine discharge and other associated findings, and were allocated equally into four groups

Group I: Cows In this group $(n=6)$ were administered intrauterine Curcuma longa extract having concentration @ $20 \mathrm{mg} / \mathrm{ml}$ dissolved in saline to make $30 \mathrm{ml}$, at $24 \mathrm{hrs}$ interval for 3 days.

Group II: Cows In this group $(n=6)$ were administered intramuscular ceftiofur sodium @ $2.50 \mathrm{mg} / \mathrm{kg} \mathrm{B.W}$. at 24 hrs interval for 3 days.

Group III: Cows In this group cows $(n=6)$ were administered intrauterine Curcuma longa extract having concentration @ $20 \mathrm{mg} / \mathrm{ml}$ dissolved in saline to make $30 \mathrm{ml}$, at $24 \mathrm{hrs}$ interval for 3 days $+25 \mathrm{gm}$ micronutrients orally for 20 days. Group IV: Cows In this group $(n=6)$ were administered intramuscular ceftiofur sodium @ 2.50 mg/kg B.W. at 24 hrs interval for 3 days $+25 \mathrm{gm}$ micronutrients orally for 20 days.

Artificial insemination was performed at the next estrus in all animals.

\section{Therapeutic efficacy}

- The efficacy was judged on the basis of time taken for

- Cessation of uterine discharge

- Resumption of cyclicity

- First service conception

\section{RESULTS AND DISCUSSION Cessation of uterine discharge}

The mean time interval required for the clearance of uterine discharge from the commencement of treatment was lowest in group IV (8.16 \pm 0.47 days) and highest in group I (10.16 \pm 0.47 days) where as in group II and III the intervals were $8.66 \pm 0.49$ and $8.50 \pm 0.42$ days, respectively. Statistical analysis revealed that the time required for the clearance of uterine discharge was significantly different between all the groups (Table 1).

The observations indicated that the mean time interval required for cessation of uterine discharge were significantly $(p<0.05)$ different between Groups after treatment. These findings are in agreement with Jain (2006) who recorded clearance of uterine discharge in $8.83 \pm 1.10$ and $9.83 \pm 0.79$ days in control and post partum metritic antibiotic along with PGF2 $\alpha$ treated buffaloes respectively.

\section{Resumption of cyclicity}

Among all the animals treated for metritis irrespective of any therapeutic regimen the first postpartum oestrus was exhibited within 100 days from calving. The mean time interval required for resumption of cyclicity was highest (98.66 \pm 4.12$)$ in group II days followed by group I

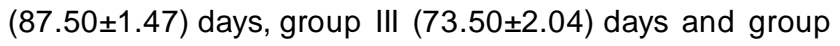
IV (66.16 \pm 1.66$)$ days, respectively.

Statistical analysis revealed that the time interval required after treatment for resumption of cyclicity was significantly different between groups (Table 2). It was observed that the time interval required after treatment for resumption of cyclicity was significantly higher $(p<0.05)$ in group 2 followed by group1 and found non significant difference in group 3 and group 4.

These findings are in agreement with Jeremejeva (2015) who observed the number of days to first service as 83.6 \pm 7.9 days in clinical endometritic cows treated with

Table 1: Time interval required for cessation of uterine discharge (Mean $\pm \mathrm{SE}$ ) in different treatment groups.

\begin{tabular}{lcc}
\hline Groups $(\mathrm{n}=6)$ & Treatment regimen & Uterine discharge Cessation interval (days) \\
\hline I & Turmeric extract & $10.16 \pm 0.47^{\mathrm{a}}$ \\
II & Ceftiofur sodium & $8.66 \pm 0.49^{\mathrm{ab}}$ \\
III & Turmeric extract + Micronutrients supplementation & $8.50 \pm 0.42^{\mathrm{b}}$ \\
IV & Ceftiofur sodium + Micronutrients supplementation & $8.16 \pm 0.47^{\mathrm{b}}$ \\
\hline
\end{tabular}

${ }^{*}$ Mean with different superscript differ significantly from each other $(p<0.05)$. 
Comparative Studies on Therapeutic Efficacy Intrauterine Turmeric Extract and Ceftiofur Sodium Alone and in Combination...

Table 2: Interval (days) required for resumption of cyclicity (Mean \pm SE) in different treatment groups.

\begin{tabular}{lcc}
\hline Groups $(\mathrm{n}=6)$ & Treatment regimen & Resumption of cyclicity (days) \\
\hline I & Turmeric extract & $87.50 \pm 1.47^{\mathrm{b}}$ \\
II & Ceftiofur sodium & $98.66 \pm 4.12^{\mathrm{a}}$ \\
III & Turmeric extract + Micronutrients supplementation & $73.50 \pm 2.04^{\mathrm{c}}$ \\
IV & Ceftiofur sodium + Micronutrients supplementation & $66.16 \pm 1.66^{\mathrm{c}}$ \\
\hline
\end{tabular}

${ }^{*}$ Mean with different superscript differ significantly from each other $(p<0.05)$.

Table 3: Conception rate in different treatment groups (\%).

\begin{tabular}{lcr}
\hline Groups $(\mathrm{n}=6)$ & Treatment regimen & Conception rate \% \\
\hline I & Turmeric extract & $50(3 / 6)$ \\
II & Ceftiofur sodium & $50(3 / 6)$ \\
III & Turmeric extract + Micronutrients supplementation & $66.66(4 / 6)$ \\
IV & Ceftiofur sodium + Micronutrients supplementation & $66.66(4 / 6)$ \\
\hline
\end{tabular}

${ }^{*}$ Figures in parenthesis indicate number of cows.

ceftiofur. These findings are also in agreement with Jain (2006) who observed first postpartum oestrus at $89 \pm 165.88$ days in group I (PGF2 $\alpha)+$ (antibiotic), and higher result than the present study as $108.50 \pm 2.36$ days in postpartum metritic buffaloes treated with antibiotic (Group II), respectively.

\section{First service conception}

All the treatment group cows which come in heat allowed for natural service or inseminated with frozen thawed semen at 12 hours interval from the onset of oestrus. All the inseminated or natural serviced cows were examined per rectally after 60 days for confirmation of pregnancy.

Conception rate observed in the present study are presented in Table 3. The conception rates from responded cows were higher $66.66 \%$ in III and IV followed by 50.00 percent in Groups, I and II respectively.

In the present study, the conception rate of Group I was $50 \%$. These findings are in agreement with Kumar et al. (2018) who recorded $50 \%$ conception rate in repeat breeder endometritic crossbred cows treated with intrauterine turmeric extract.

The present findings in Group II are slightly lower than the finding of Jeremejeva (2015) who observed 64\% first service conception rate in cows suffered with clinical endometritis, treated with ceftiofur. The present findings in Group III are slightly higher than the finding of Kumar et al. (2018) who observed $62.5 \%$ conception rate in repeat breeder endometritic crossbred cows treated with intrauterine hydro-alcoholic turmeric.

\section{ACKNOWLEDGEMENT}

To dean of the college, head of the department, major advisor and entire staff of the establishments that were part of this work, for their unconditional support and and collaboration.

\section{REFERENCES}

Abdullah, M. Mohanty, T.K., Patbandha, T.K., Bhakat, M., Madkar, A.R., Kumaresan and Mohanty, A.K. (2017). Pregnancy diagnosis - positive rate and conception rate as indicator of farm reproductive performance. Indian Journal of Animal Research. 51(1): 170-174.
Agarwal, S.K., Pandey, N.N. and Shanker, U. (1985). Serum protein, inorganic phosphorous and blood glucose in relation to different phases of reproduction in crossbred cattle. Indian Journal of Animal Reproduction. 6: 23-25.

Bhaumik, A., Sharma, M.C. and Lal, S.B. (1992). Therapeutic efficacy of streptopenicillin in postpuerperal metritis in cows. Indian Journal of Veterinary Research. 1: 32-33.

Cairoli, F., Ferrario, L., Carte, S. and Soldano, F. (1993). Efficacy of oxytetracycline and tetracycline benzydamine in the prevention of infection after placental retention in cattle. Veterinary Record. 133(16): 394-395.

Cunha, B.A. (2001). Antibiotics side effects. Medical Clinics of North America. 85: 149-185.

Evans, C.E., Banso, A. and Samuel, O.A. (2002). Efficacy of some nupe medicinal plants against Salmonella typhi: An in vitro study. Journal of Ethnopharmacology. 80: 21-24.

Ghazanfari T., Hassan, Z.N. and Ebrahimi, M. (2002). Immunomodulatory activity of a protein isolated from garlic extract on delayed type of hypersensitivity. International Immunopharmacology. 2(11): 1541-1549.

Gupta, S., Gupta, H.K. and Soni, J. (2005) Effect of vitamin E and selenium supplementation on concentrations of plasma cortisol and erythrocyte lipid peroxides and the incidence of retained foetal membranes in crossbred dairy cattle. Theriogenology. 64: 1273-1286.

Husband, J. (2006). Retained fetal membranes and vulval discharges in a dairy herd. United Kingdom Veterinary Livestock. 11(1): 39-42.

Hussain, A.M. and Denial, R.C.W. (1992). Serum progesterone concentrations and blood neutrophil alkaline phosphatase activity in cows following normal and abnormal parturition, Reproduction in Domestic Animals. 27(4): 229-235.

Jain, S.K. (2006). Studies on post-partum metritis in buffaloes. M.V.Sc. Thesis, Departement of Animal Reproduction, Gynaecology and Obstetrics, Jawaharlal Nehru Krishi Vishwavidyalaya, Jabalpur.

Jeremejeva, J. (2015). Prostaglandin $\mathrm{f} 2 \alpha$ and parenteral antibiotics as a treatment of postpartum metritis and endometritis, and possible relation of acute phase proteins with subsequent fertility in dairy cows. P.h.D. Thesis, Institute of Veterinary Medicine and Animal Sciences Estonian University of Life Sciences, Vienna, Austria. 
Khasatiya, C.T., Dhami, A.G., Ramani, V.P., Savalia, F.P. and Kavani, F.S. (2005). Reproductive performance and mineral profile of postpartum fertile and infertile Surti buffaloes. Indian Journal of Animal Reproduction. 26(2): 145-148.

Kumar, A., Gupta, H.P. and Prasad, S. (2018). Studies on the immunomodulatory and therapeutic efficacy of turmeric (curcuma longa) on endometritis in repeat breeding crossbred cows. International Journal of Agriculture Sciences. 10(2): 5069-5072.

Kumar, R., Sinha M.P., Kumar, A., Kurmi, D.J. and Chaudhary, P.K. (2018). Management of endometritic repeat breeding cross bred cow with herbal extract to improve the conception rate. International Journal of Current Microbiology and Applied Sciences. 7: 4621-4626.

Logan, F.F., Rice, D.A. Smyth, J.A. and Ellis, W.A. (1990). Weak calf syndrome and parenteral- selenium supplementation. Veterinary Record. 126: 163-164.

Nair, R., Kalariya, T. and Chanda, S. (2005). Antibacterial Activity of Some Selected Indian Medicinal Flora. Turkish Journal of Biology. 29: 41-47.

Patil, R.V. and Deshpande, B.R. (1979). Changes in body weight, blood glucose and serum proteins in relation to the appearance of postpartum oestrus in Gir cows. Journal of Reproduction and Fertility. 57: 25-27.

Prajapati, S.B., Ghodasara, D.J., Joshi, B.P., Prajapati, K.S. and Jani, V.R. (2005). Etiopathological study of endometritis in repeat breeder buffaloes. Buffalo Journal. 2: 145-165.
Sarkar, B., Ray, K. and Sarkar, U. (2016). Prevalence of uterine infection in relation to certain haematological and biochemical changes of blood serum in dairy cows. Indian Journal of Animal Research. 50(4): 557- 560.

Sarkar, P., Patra, M.K. and Kumar, H. (2016). Strategic treatment with immunomodulators to resolve endometritis in cow: A review .Agricultural Review. 37(3): 186-195.

Sharma, M.C., Joshi, C. and Kumar, M. (2005). Micro mineral deficiency disorders and treatment: A review. Indian Journal of Animal Science. 75(2): 246- 257.

Singh, S. and Vadnere, S.V. (1987). Short course on role of minerals and vitamins in livestock health and production, (In Kumar, H. (2004) Reproductive Disorders Due to Deficiency of Minerals and Vitamins in Livestock. IVRI, Izatnagar, U.P.). Indian Journal of Animal Reproduction. 8: 46-49.

Snedecor, G.W. and Cochran, W.G. (1994). Statistical Methods, $8^{\text {th }}$ Edn. The lowa state college press, INC. American lowa, (USA). pp 237-238.

Subapriya, R. and Nagini, S. (2005). Medicinal properties of Neem leaves: a review. Current Medicinal Chemistry Anticancer Agents. 5(2): 146-149.

Walia, R., Ravikanth, K., Maini, S. and Sood, D. (2010). Therapeutic efficacy of AV/UTL/17 in cases of postpartum gynaecological disorders in cows: a field study. Veterinary World. 3(12): 544-545. 